\title{
BIOELECTRICAL PHASE ANGLE, MUSCLE DAMAGE MARKERS AND INFLAMMATORY RESPONSE AFTER A COMPETITIVE MATCH IN PROFESSIONAL SOCCER PLAYERS
}

\author{
HELIODORO MOYA-AMAYA, ANTONIO MOLINA-LÓPEZ1, ANTONIO JESÚS BERRAL- \\ AGUILAR $^{2}$, DANIEL ROJANO-ORTEGA2 ${ }^{2}$, CARLOS JAVIER BERRAL-DE LA ROSA², \\ FRANCISCO JOSÉ BERRAL-DE LA ROSA² \\ 'Department of Nutrition of Udinese Calcio, Udine, Italy \\ 2 CTS-595 Research Group. Department of Informatics and Sports, University Pablo de Olavide, Seville, Spain
}

Mailing address: Daniel Rojano-Ortega, Department of Informatics and Sports, University Pablo de Olavide, Seville, Spain, 1 María Fulmen Street, 41019-Seville, e-mail: drojort@upo.es

\begin{abstract}
Introduction. The purposes of this study were 1) to evaluate changes from baseline levels in bioelectrical phase angle (PhA) and markers of muscle damage and inflammation in professional players $36 \mathrm{~h}$ after a soccer match, and 2) to analyze the relationships between $\mathrm{PhA}$ and markers of muscle damage and inflammation in order to investigate if $\mathrm{PhA}$ might be a useful parameter to monitor recovery. Material and methods. Eighteen male professional soccer players participated in this study. Plasma lactate dehydrogenase (LDH) and creatine kinase (CK) activities, plasma C-reactive protein (CRP) and interleukin-6 (IL-6) concentrations, and PhA were measured before and $36 \mathrm{~h}$ after a competitive match. Results. Changes in LDH and CK 36 $\mathrm{h}$ after the match were greater than their reference change values (RCV). Changes in CRP and IL-6 were, however, lower than their corresponding RCV. $36 \mathrm{~h}$ after the match, significant correlations were observed between PhA and LDH $(\mathrm{r}=0.714, \mathrm{p}=$ 0.001), PhA and CK $(r=0.787, p=0.000)$, and PhA and CRP $(r=0.554, p=0.017)$. Conclusions. Although IL-6 and CRP have been traditionally analyzed together to monitor inflammation after intense exercise, since $36 \mathrm{~h}$ after the match they have already returned or started to return to baseline levels, the use of them alone is not a good option to monitor inflammation throughout recovery. PhA might be used as a predictor of muscle damage and inflammation, but further studies covering the whole recovery period are warranted.
\end{abstract}

Key words: soccer, phase angle, muscle damage, inflammation, recovery

\section{Introduction}

Strenuous physical exercise is one of the most common causes of muscle damage and it occurs when muscles produce more physical work than they are used to producing [1]. The high level of physical exercise evokes mechanical disruption to sarcomeres and triggers an inflammatory response which is part of muscle repair and regeneration [2,3]. This inflammatory response accentuates the loss of force production caused by the direct muscle damage and increases muscle soreness, which has a negative impact on exercise performance and delays recovery $[4,5]$.

Biochemical markers of muscle damage and inflammation are usually monitored to study and optimize recovery after exercise. Creatine kinase (CK) and lactate dehydrogenase (LDH) are two of the most common markers of direct muscle damage $[1,6,7]$ and, according to Nowakowska et al. [8], CK and LDH together with aspartate aminotransferase and creatinine levels could constitute a useful set of markers for monitoring recovery periods in soccer players. Among the large number of biochemical markers of inflammation, interleukin-6 (IL-6) and C-reactive protein (CRP) are two of the most frequently used in sport $[5,6,7]$.

Eccentric contractions cause more muscle damage than concentric contractions, especially at longer muscle lengths, when the muscle generates excessive strain during lengthening, and extensive myofibrillar disruption occurs [4]. Soccer is an intermittent sport with a powerful eccentric component [9] due to the high number of accelerations, decelerations and changes of directions [10], as well as jumps and other explosive activities [11]. It is precisely the high repetition of eccentric contractions during a competitive match that leads to greater levels of muscle damage and inflammation than other team sports [12].

There exist different methods to accelerate recovery after maximum exercise [13]. Previous investigations have reported high levels of muscle damage and inflammation up to 72 hours after a soccer match [14, 15], but in soccer it is not uncommon to have only 3-4 days between consecutive matches, which may not be enough time to full recovery [14]. This is the reason why monitoring useful markers of muscle damage and inflammation is essential to investigate the efficiency of the different strategies to accelerate recovery of muscle function.

Bioelectrical impedance analysis (BIA) is an inexpensive and non-invasive method for the assessment of body composition and nutritional status. BIA measures electrical parameters, such as resistance, reactance, bioelectrical phase angle $(\mathrm{PhA})$ and impedance, which are called raw electrical impedance variables. These parameters are introduced into population-specific equations to calculate body composition, but these equations are only accurate under certain circumstances [17]. Raw variables are not, however, influenced by the equations that may affect body composition compartments [18].

BIA devices submit the human body to a weak, alternating current at one or more frequencies, detect the drop in voltage 
as the current flows, and calculate and record the raw parameters [19]. Among those parameters, PhA has been widely used in clinical studies as an indicator of cellular health and cell membrane integrity $[20,21]$, and it is supposed that the higher the $\mathrm{PhA}$ value, the better the cell function [22]. PhA is obtained from the arctangent of the reactance to resistance ratio. Resistance is the decrease in voltage reflecting conductivity through ionic solutions and reactance is the delay in the flow of current due to cell membranes and tissue interfaces [21].

In sports, $\mathrm{PhA}$ has been recently used as an indicator of physical activity and nutritional status $[20,23]$. In middle-distance athletes, $\mathrm{PhA}$ was positively associated with athletic performance, although it was not demonstrated whether $\mathrm{PhA}$ was adequate to monitor improvements in running performance [24]. In male soccer players it was observed that, compared with the elite level, players of a lower performance level had lower phase angles [25].

Since $\mathrm{PhA}$ is considered an indicator of cellular health and cell membrane integrity, it is reasonable to presume that there might be a relationship between $\mathrm{PhA}$ and markers of muscle damage and inflammation after intense exercise. However, little research has been carried out on this subject. Only Tomeleri et al. [26] studied the correlations between changes in PhA and changes in tumor necrosis factor alpha (TNF- $\alpha$ ), CRP, IL-6 and IL-10 in older women after 12 weeks of resistance training. They found significant negative correlations between changes in $\mathrm{PhA}$ and changes in TNF- $\alpha$ and CRP, and a significant positive correlation between changes in PhA and changes in IL-10. No significant correlation was found with changes in IL-6. However, the authors did not measure any direct marker of muscle damage and measurements were not made after strenuous physical exercise.

Monitoring muscle damage and inflammation is particularly important in soccer, and $\mathrm{PhA}$ may be an appropriate variable to estimate muscle damage and inflammation with a quick, non-invasive and relatively inexpensive method. Therefore, the purposes of this study were 1) to evaluate changes from baseline levels in PhA and markers of muscle damage and inflammation in professional players $36 \mathrm{~h}$ after a soccer match, and 2) to analyze the relationships between $\mathrm{PhA}$ and markers of muscle damage and inflammation in order to investigate if $\mathrm{PhA}$ might be a useful parameter to monitor recovery.

\section{Material and methods}

\section{Participants}

The study was performed by the Department of Nutrition of an Italian first division soccer team and the Research Group of a Spanish University. Eighteen male professional soccer players (age $26.44 \pm 3.03$ years; height $185.07 \pm 4.37 \mathrm{~cm}$; weight 84.87 $\pm 7.29 \mathrm{~kg}$ ) from an Italian first division soccer team participated in this study. The participants were evaluated before and $36 \mathrm{~h}$ after a competitive match, over a period of about one month during the first half of the season (matches 7-10). The players were included in the analysis only if they played for more than 45 minutes during the match, and goalkeepers were excluded. None of the players had suffered severe performance-limiting injuries from the beginning of the season.

This study was approved by the University Research Ethics Committee and was conducted in accordance with the Declaration of Helsinki regarding the use of human subjects. All the players provided written informed consent to participate in the study.

\section{Biochemical analyses}

The blood extraction was performed between 8 a.m. and 10 a.m., after an overnight fast of at least 8 hours, in the morning of the competitive match and $36 \mathrm{~h}$ after the match. Blood samples were collected from an antecubital arm vein with the subject in a seated position. Plasma CK and LDH activities and concentrations of CRP and IL- 6 were determined by the same laboratory (Synlab Italia S.R.L.). The samples were withdrawn into lithium-heparin tubes, using EDTA as anticoagulant, then centrifuged at $3000 \mathrm{rpm}$ for $10 \mathrm{~min}$ to separate the plasma and stored at $-20^{\circ} \mathrm{C}$ until analysis.

LDH activity was assessed with a colorimetric kinetic method using a commercial test kit from Randox (REF 90.29.2). CK activity was determined by an IFCC kinetic optimized method with a commercial test kit from Randox (REF 90.15.4). An immunoturbidimetric method was used to measure CRP concentration with a specific test kit from Randox (REF 90.72.3). IL-6 was quantified with a chemiluminescence method using a specific test kit from Randox (REF 90.70.2). The coefficients of variation were $1.54 \%$ for $\mathrm{LDH}, 4.55 \%$ for CK, $3.0 \%$ for CRP and $7.2 \%$ for IL-6.

\section{PhA assessment}

BIA was performed with a body composition analyzer (Tanita MC-780 MA, Tanita Corp., Tokyo, Japan), by the same professional. The evaluation was undertaken between 8 a.m. and 10 a.m., after an overnight fast of at least 8 hours, in the morning of the competitive match and $36 \mathrm{~h}$ after the match. The subjects had refrained from moderate or intense physical exercise in the previous $24 \mathrm{~h}$. Before performing the assessment, participants urinated and were instructed to remove metallic elements from their bodies. Players were measured while standing erect with bare feet on the foot-pads and holding the handgrips making contact with the four hand-pads. The device emitted an alternating sinusoidal electric current of $900 \mu \mathrm{A}$ operating at 5, 50 and $250 \mathrm{kHz}$ (multi-frequency). Standard measurements were performed according to the manufacturer guidelines. PhA was calculated from the arctangent of reactance to resistance ratio of the whole body, at a frequency of $50 \mathrm{~Hz}$ [20].

\section{Statistical Analysis}

Statistical analysis was performed using SPSS software v. 22.0 (SPSS Inc., USA). Means and standard deviations of all variables were calculated, before and $36 \mathrm{~h}$ after the match. Using the analytical and within-subject coefficients of variation provided by the European Biological Variation Study (EuBIVAS) [27, 28], reference change values (RCV) were calculated for LDH, CK and CRP. As variability of IL- 6 has not been established by EuVIBAS, we took the data reported by Aziz et al. [29]. RCV were used to assess significance of the changes 36 $\mathrm{h}$ after the match with respect to pre-match values, and were determined as: $\mathrm{RCV}=2^{1 / 2} \times 1.96 \times\left(\mathrm{CV}_{\mathrm{A}}^{2}+\mathrm{CV}_{\mathrm{I}}^{2}\right)^{1 / 2}$, where $\mathrm{CV}_{\mathrm{A}}$ is analytical variation and CVI is within-subject biological variation [30].

Shapiro-Wilk test was applied to test data normality. As this condition was always fulfilled, Pearson's $\mathrm{r}$ correlation coefficients were calculated to evaluate the possible relationships between PhA and the rest of variables measured, before and $36 \mathrm{~h}$ after the match. They were interpreted according to the following criteria: $\mathrm{r}<0.1$, trivial; $0.1<\mathrm{r} \leq 0.3$, weak; $0.3<\mathrm{r}$ $\leq 0.5$, moderate; $0.5<\mathrm{r} \leq 0.7$, strong; $0.7<\mathrm{r} \leq 0.9$, very strong; and $\mathrm{r}>0.9$, almost perfect [31]. If a significant correlation was found, linear regression was performed to predict changes in the dependent variable from changes in PhA. Coefficients of deter- 
mination $\left(\mathrm{R}^{2}\right)$ were used to represent the goodness of the regression equation. The statistical level of significance was set as $\mathrm{p}<0.05$ for all analyses.

\section{Results}

Means and standard deviations of all the variables measured, before and $36 \mathrm{~h}$ after the match, are presented in Table 1. Changes pre-post-match and RCV are also presented in Table 1. Changes observed in LDH and CK were statistically significant because they were greater than their corresponding RCV. However, changes produced in CRP and IL-6 were not statistically significant.

No significant correlations between PhA and the rest of the study variables were found before the match. However, the present study found important relationships $36 \mathrm{~h}$ after the match between PhA and most biochemical markers measured (Tab. $2)$. Very strong correlations were observed between $\mathrm{PhA}$ and LDH $(r=0.714, \mathrm{p}=0.001)$ and between PhA and CK $(\mathrm{r}=0.787$, $\mathrm{p}=0.000)$ and a strong correlation was found between $\mathrm{PhA}$ and CRP $(r=0.554, p=0.017)$. Figure 1 shows coefficients of determination and regression equations between $\mathrm{PhA}$ and markers of muscle damage, $36 \mathrm{~h}$ after the match.

\section{Discussion}

The first purpose of this study was to assess changes from baseline levels in PhA and markers of muscle damage and inflammation in professional soccer players $36 \mathrm{~h}$ after a soccer match. Changes in markers of muscle damage were greater than their respective RCV, which means that they were due to the muscle damage induced by the match, and not to biological variations. Change in CK activity $36 \mathrm{~h}$ after the match (Tab. 1) is in good agreement with that found by Beattie et al. [32], who measured plasma CK activity during the season, in a group of 18 elite soccer players, one day before a competition match and $48 \mathrm{~h}$ after the match. They found that $48 \mathrm{~h}$ after the match, CK activity was of $648 \mathrm{U} \cdot \mathrm{L}^{-1}$, which was approximately $50 \%$ higher than their baseline value. Silva et al. [15], also assessed CK activity in a group of 7 male professional soccer players before, $24 \mathrm{~h}$ after, $48 \mathrm{~h}$ after and $72 \mathrm{~h}$ after the last match of the championship. However, they observed that CK activity peaked $24 \mathrm{~h}$ after the match and decreased to $560.6 \pm 62.1$ U.L-1 $48 \mathrm{~h}$ after the match, which was $86.5 \%$ higher than baseline values. The
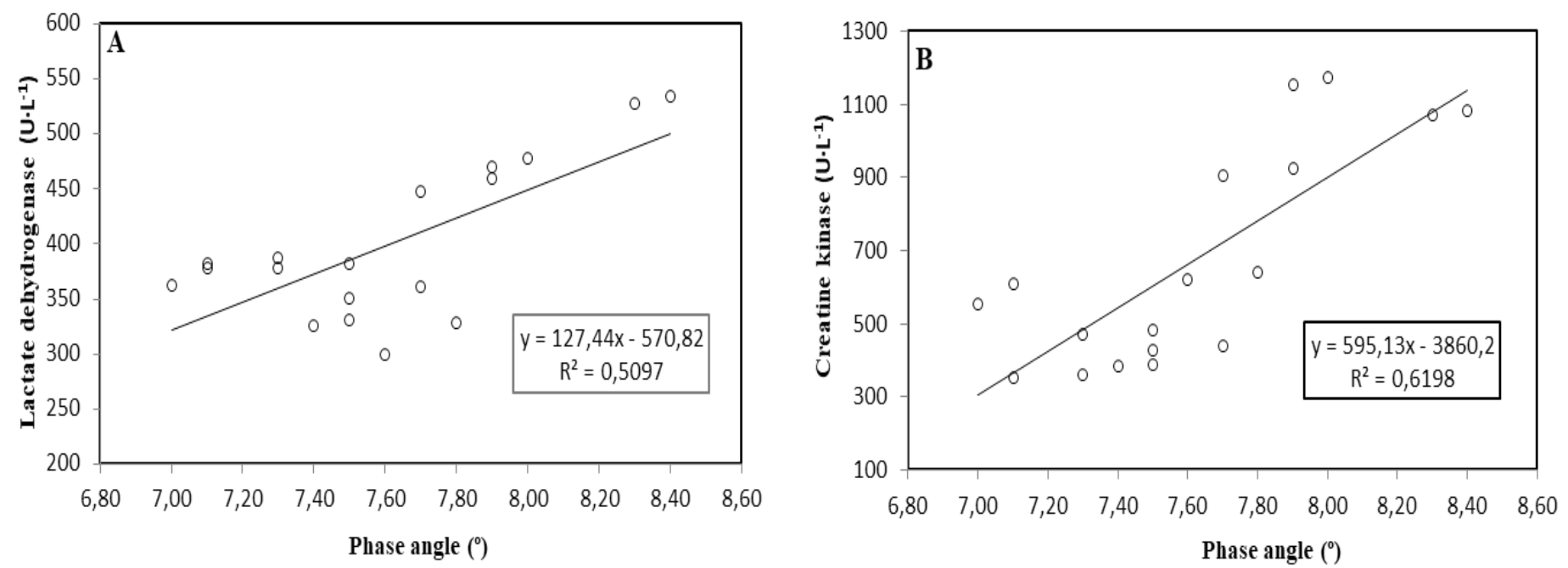

Figure 1. Correlation of phase angle with (A) plasma lactate dehydrogenase activity and (B) creatine kinase activity

Table 1. Means and standard deviations of the study variables before and $36 \mathrm{~h}$ after the match. Changes pre-post-match and reference change values.

\begin{tabular}{|c|c|c|c|c|}
\hline \multirow[t]{2}{*}{ Variables } & Pre-match & $\begin{array}{l}36 \mathrm{~h} \text { post- } \\
\text { match }\end{array}$ & \multirow[t]{2}{*}{$\begin{array}{l}\text { Changes pre- } \\
\text { post-match }(\%)\end{array}$} & \multirow[t]{2}{*}{$\begin{array}{r}\mathrm{RCV} \\
(\%)\end{array}$} \\
\hline & mean $\pm \mathrm{sd}$ & mean $\pm s d$ & & \\
\hline $\operatorname{PhA}\left({ }^{\circ}\right)$ & $\begin{array}{c}7.69 \pm \\
0.38\end{array}$ & $\begin{array}{c}7.61 \pm \\
0.39\end{array}$ & -1.0 & --- \\
\hline $\mathrm{LDH}\left(\mathrm{U} \cdot \mathrm{L}^{-1}\right)$ & $\begin{array}{c}243.83 \pm \\
58.83\end{array}$ & $\begin{array}{c}399.17 \pm \\
70.32\end{array}$ & $63.7^{*}$ & 15.6 \\
\hline CK $\left(U \cdot L^{-1}\right)$ & $\begin{array}{c}384.28 \pm \\
96.53\end{array}$ & $\begin{array}{c}669.39 \pm \\
297.76\end{array}$ & $74.2^{*}$ & 44.4 \\
\hline $\mathrm{CRP}\left(\mathrm{mg} \cdot \mathrm{dL}^{-1}\right)$ & $\begin{array}{c}0.11 \pm \\
0.02\end{array}$ & $\begin{array}{c}0.18 \pm \\
0.04\end{array}$ & 66.2 & 85.3 \\
\hline $\mathrm{IL}-6\left(\mathrm{pg} \cdot \mathrm{mL}^{-1}\right)$ & $\begin{array}{c}1.77 \pm \\
0.17\end{array}$ & $\begin{array}{c}2.41 \pm \\
0.79\end{array}$ & 36.2 & 66.2 \\
\hline
\end{tabular}

PhA - phase angle; LDH - lactate dehydrogenase; CK - creatine kinase; CRP - C-Reactive protein; IL-6 - interleukin 6; sd - standard deviation; RCV - reference change values; * - significant differences between post-match and pre-match values $(\mathrm{p}<0.05)$.

Table 2. Pearson correlation coefficients between $\mathrm{PhA}$ and biochemical markers $36 \mathrm{~h}$ after the match.

\begin{tabular}{|c|c|c|c|c|}
\hline & LDH & CK & CRP & IL-6 \\
\hline PhA & $0.714^{* *}$ & $0.787^{* * *}$ & $0.554^{*}$ & 0.172 \\
\hline
\end{tabular}

PhA - Phase Angle; LDH - lactate dehydrogenase; CK - creatine kinase; CRP - C-Reactive protein; IL-6 - interleukin-6; * $-\mathrm{p}<0.05$; ${ }^{* *}-\mathrm{p}<0.01$; *** $-\mathrm{p}<0.001$.

fact that they performed measurements after the last match of the championship and the high biological variations of CK are probably the reasons for these differences.

Change in LDH activity $36 \mathrm{~h}$ after the match (Tab. 1) is a bit lower than those observed in previous investigations with professional soccer players [12,33], probably because our players started from higher baseline levels. These differences in LDH activity before the match may be due to the fact that participants from those studies were measured at the beginning of the season [12] or off the season [33], and their LDH levels were, therefore, lower than ours. 
With regard to markers of inflammation, changes from baseline levels $36 \mathrm{~h}$ after the match in CRP and IL-6 were lower than their corresponding RCV, which might indicate that the competitive match did not induce enough inflammation. After intense exercise, muscle damage triggers an inflammatory response, resulting in an increase in IL-6 concentration which usually peaks immediately after exercise and returns to baseline levels within $24 \mathrm{~h}[12,33,34]$. Increased circulating IL-6 concentration stimulates the synthesis of acute-phase proteins such as CRP, which frequently peaks $24 \mathrm{~h}$ after exercise [15, 33, 34].

Therefore, in agreement with previous investigations, our results do not indicate that the competitive match did not induce inflammation but that $36 \mathrm{~h}$ after the match, CRP and IL-6 values had already returned or started to return to baseline levels. Thus, even if IL-6 and CRP have been traditionally analyzed together to monitor inflammation after intense exercise, the use of them alone is not a good option to monitor inflammation during the whole recovery period.

Changes in PhA were negligible (1\%), which means that the match did not induce a change in PhA or it returned to baseline levels before $36 \mathrm{~h}$. These findings cannot be compared with previous results owing to the lack of investigations studying the changes in PhA during the recovery period after a soccer match. However, our average value in the morning before the match $\left(7.69 \pm 0.38^{\circ}\right)$ is consistent with the result obtained by Levi-Micheli et al. [25]. They studied a group of 219 elite players of Italian first and second divisions, and obtained an average value of $7.7 \pm 0.6^{\circ}$, measured before a midweek training session in the first half of the season.

The second purpose of this study was to analyze the relationships between PhA and markers of muscle damage and inflammation, and to investigate if $\mathrm{PhA}$ may be useful to monitor recovery. It was expected to find negative correlations between $\mathrm{PhA}$ and markers of muscle damage and inflammation, because $\mathrm{PhA}$ is considered an indicator of cellular health and cell membrane integrity $[20,21]$.

No significant correlation was found between $\mathrm{PhA}$ and the biochemical markers measured the morning before the match. Nevertheless, we obtained strong positive correlations between $\mathrm{PhA}$ and LDH or CK and a moderate positive correlation between PhA and CRP (Tab. 2). These results are not in line with those obtained by Nescolarde et al. [35] and Francavilla et al. [36], who concluded that PhA decreased with increasing muscle injury severity in soccer players. However, they used a localized bioimpedance and, in addition, they measured injured lower limbs. The present study evaluated PhA of the whole body and, even if our soccer players probably suffered from exercise-induced muscle damage, they were not really injured. Therefore, our findings cannot be compared with theirs.

To the best of our knowledge, just two studies analyzed the correlation between $\mathrm{PhA}$ and markers of muscle damage or inflammation. Tomeleri et al. [26] found a very strong negative correlation between increases in PhA and increases in CRP, but those increases were not calculated before and after intense exercise, but before and after a 12-week resistance training, and measures were carried out a minimum of $48 \mathrm{~h}$ since the last physical exercise session. Beverashvili et al. [37] found a small/ moderate negative correlation between changes in $\mathrm{PhA}$ over time and changes in IL- 6 in patients on maintenance hemodialysis, but those results are not comparable to ours, either.

A possible explanation for our unexpected results could be the total distance covered by the players during the match, but no significant correlation was found with PhA or any of the biomarkers measured (data not shown). Moreover, significant correlations with total walking distance, total running distance or distances covered at different speeds during the match were not observed. The reasons why we obtained those positive significant correlations are then unclear but the fact that they exist indicates that $36 \mathrm{~h}$ after the match, the greater the $\mathrm{PhA}$, the higher the muscle damage and inflammation.

The main limitations of this study are the consequences of the difficulty to evaluate several times in $48 / 72 \mathrm{~h}$ players from European First Division soccer teams. It would have been more interesting to analyze all the variables measured before the match, and to observe their changes during the whole recovery period. Notwithstanding that, our greatest strength is that this is the first study to correlate PhA with markers of muscle damage and inflammation before the match and at a certain point of recovery, and may serve as a reference for future studies evaluating different time points of recovery or even several consecutive matches throughout the season.

\section{Conclusions}

A soccer match induces a marked rise in biochemical markers of muscle damage and inflammation, particularly in CK, LDH, CRP and IL-6. IL-6 and CRP have been traditionally analyzed together to monitor inflammation after intense exercise but, since $36 \mathrm{~h}$ after the match they had already returned or started to return to baseline levels, the use of them alone is not a good option to monitor inflammation during the whole recovery period. The moderate/strong positive correlations observed between $\mathrm{PhA}$ and LDH, CK and CRP, $36 \mathrm{~h}$ after the competitive match suggest that after intense exercise, $\mathrm{PhA}$ is inversely related to cell membrane integrity in healthy soccer players, and might be used as a predictor of muscle damage and inflammation throughout recovery.

\section{References}

1. Brancaccio P., Lippi G., Maffulli N. (2020). Biochemical markers of muscular damage. Clinical Chemistry and Laboratory Medicine 48(6), 757-767. DOI: 10.1515/CCLM.2010.179.

2. Chazaud B. (2016). Inflammation during skeletal muscle regeneration and tissue remodeling: application to exercise-induced muscle damage management. Immunology and Cell Biology 94(2), 140-145. DOI: 10.1038/icb.2015.97.

3. Powers S.K., Jackson M.J. (2008). Exercise-induced oxidative stress: Cellular mechanisms and impact on muscle force production. Physiological Reviews 88(4), 1243-1276. DOI: 10.1152/physrev.00031.2007.

4. Howatson G., van Someren K.A. (2008). The prevention and treatment of exercise-induced muscle damage. Sports Medicine 38(6), 483-503. DOI: 10.2165/00007256200838060-00004.

5. Rojano D., Molina A., Moya H., Berral F.J. (2021). Tart cherry and pomegranate supplementations enhance recovery from exercise-induced muscle damage: a systematic review. Biology of Sport 38(1), 97-111. DOI: 10.5114/biolsport.2020.97069.

6. Fernández-Lázaro D., Mielgo-Ayuso J., Seco J., Córdova A., Caballero A., Fernández-Lázaro C. (2020). Modulation of exercise-induced muscle damage, inflammation, and oxidative markers by curcumin supplementation in a physically active population: A systematic review. Nutrients 12(2), 501. DOI: 10.3390/nul2020501.

7. Luti S., Modesti A., Modesti P.A. (2020). Inflammation, peripheral signals and redox homeostasis in athletes who 
practice different sports. Antioxidants (Basel) 9(11), 1065. DOI: 10.3390/antiox9111065.

8. Nowakowska A., Kostrzewa-Nowak D., Buryta R., Nowak R. (2019). Blood biomarkers of recovery efficiency in soccer players. International Journal of Environmental Research and Public Health 16(18), 3279. DOI: 10.3390/ ijerphl6183279.

9. Nedelec M., McCall A., Carling C., Legall F., Berthoin S., Dupont G. (2012). Recovery in soccer: part I - post-match fatigue and time course of recovery. Sports Medicine 42(12), 997-1015. DOI: 10.2165/11635270-000000000-00000.

10. Varley M.C., Aughey R.J. (2013). Acceleration profiles in elite Australian soccer. International Journal of Sports Medicine 34(1), 34-39. DOI: 10.1055/s-0032-1316315.

11. Andersson H., Ekblom B., Krustrup P. (2008). Elite football on artificial turf versus natural grass: movement patterns, technical standards, and playerimpressions. Journal of Sports Science 26(2), 113-122. DOI: 10.1080/02640410701422076.

12. Souglis A., Bogdanis G.C., Giannopoulou I., Papadopoulos Ch., Apostolidis N. (2015). Comparison of inflammatory responses and muscle damage indices following a soccer, basketball, volleyball and handball game at an elite competitive level. Research in Sports Medicine 23(1), 59-72. DOI: 10.1080/15438627.2014.975814.

13. Ferreira J.C., Da Silva-Carvalho R.G., Moreira-Barroso T., Szmuchrowski L.A., Sledziewski D. (2011). Effect of different types of recovery on blood lactate removal after maximum exercise. Polish Journal of Sport and Tourism 18, 105111. DOI: 10.2478/v10197-011-0008-4.

14. Fatouros I.G., Chatzinikolaou A., Douroudos I.I., Nikolaidis M.G., Kyparos A. et al. (2010). Time-course of changes in oxidative stress and antioxidant status responses following a soccer game. Journal of Strength and Conditioning Research 24(12), 3278-3286. DOI: 10.1519/JSC.0b013e3181b60444.

15. Silva J.R., Ascensao A., Marques F., Seabra A., Rebelo A., Magalhaes J. (2013). Neuromuscular function, hormonal and redox status and muscle damage of professional soccer players after a high-level competitive match. European Journal of Applied Physiology 113(9), 2193-2201. DOI: 10.1007/ s00421-013-2633-8.

16. Altarriba-Bartes A., Peña J., Vicens-Bordas J., Casals M., Peirau X., Calleja-González J. (2021). The use of recovery strategies by Spanish first division soccer teams: a cross-sectional survey. The Physician and Sportsmedicine 49(3), 297-307. DOI: 10.1080/00913847.2020.1819150.

17. Deutz N.E.P., Ashurst I., Ballesteros M.D., Bear D.E., Cruz-Jentoft A.J. et al. (2019). The underappreciated role of low muscle mass in the management of malnutrition. Journal of the American Medical Directors Association 20(1), 22-27. DOI: 10.1016/j.jamda.2018.11.021.

18. Bosy-Westphal A., Danielzik S., Dörhöfer R.P., Later W., Wiese S., Müller M.J. (2006). Phase angle from bioelectrical impedance analysis: Population reference values by age, sex, and body mass index. Journal of Parenteral and Enteral Nutrition 30(4), 309-316. DOI: 10.1177/0148607106030004309.

19. Earthman C.P. (2015). Body composition tools for assessment of adult malnutrition at the bedside: a tutorial on research considerations and clinical applications. Journal of Parenteral and Enteral Nutrition 39(7), 787-822. DOI: $10.1177 / 0148607115595227$.

20. Koury J.C., Trugo N.M.F., Torres A.G. (2014). Phase angle and bioelectrical impedance vectors in adolescent and adult male athletes. International Journal of Sports Physiology and Performance 9(5), 798-804. DOI: 10.1123/ijspp.2013-0397.
21. Norman K., Stobäus N., Pirlich M., Bosy-Westphal A. (2012). Bioelectrical phase angle and impedance vector analysis-clinical relevance and applicability of impedance parameters. Clinical Nutrition 31(6), 854-861. DOI: 10.1016/j. clnu.2012.05.008.

22. Gonzalez M.C., Barbosa-Silva T.G., Bielemann R.M., Gallagher D., Heymsfield S.B. (2016). Phase angle and its determinants in healthy subjects: influence of body composition. American Journal of Clinical Nutrition 103(3), 712-716. DOI: 10.3945/ajcn.115.116772.

23. Mundstock E., Amaral M.A., Baptista R.R., Sarria E.E., Grecco R.R. et al. (2019). Association between phase angle from bioelectrical impedance analysis and level of physical activity: systematic review and meta-analysis. Clinical $\mathrm{Nu}$ trition 38(4), 1504-1510. DOI: 10.1016/j.clnu.2018.08.031.

24. Genton L., Mareschal J., Norman K., Karsegard V.L., Delsoglio M. et al. (2020). Association of phase angle and running performance. Clinical Nutrition ESPEN 37, 65-68. DOI: 10.1016/j.clnesp.2020.03.020.

25. Levi-Micheli M., Pagani L., Marella M., Gulisano M., Piccoli A. et al. (2014). Bioimpedance and impedance vector patterns as predictors of league level in male soccer players. International Journal of Sports Physiology and Performance 9(3), 532-539. DOI: 10.1123/ijspp.2013-0119.

26. Tomeleri C.M., Ribeiro A.S., Cavaglieri C.R., Deminice R., Schoenfeld B.J. et al. (2018). Correlations between resistance training-induced changes on phase angle and biochemical markers in older women. Scandinavian Journal of Medicine E Science in Sports 28(10), 2173-2182. DOI: 10.1111/ sms.13232.

27. Carobene A., Røraas T., Sølvik U.Ø., Sverresdotter M., Sandberg S. et al. (2017). Biological variation estimates obtained from 91 healthy study participants for 9 enzymes in serum. Clinical Chemistry 63(6), 1141-1150. DOI: 10.1373/ clinchem.2016.269811.

28. Carobene A., Aarsand A.K., Guerra E., Bartlett W.A., Coșkun A. et al. (2019). European Biological Variation Study (EuBIVAS): Within- and between-subject biological variation data for 15 frequently measured proteins. Clinical Chemistry 65(8), 1031-1041. DOI: 10.1373/clinchem.2019.304618.

29. Aziz N., Detels R., Quint J.J., Gjertson D., Ryner T., Butch A.W. (2019). Biological variation of immunological blood biomarkers in healthy individuals and quality goals for biomarker tests. BMC Immunology 20, ID: 33. DOI: 10.1186/ s12865-019-0313-0.

30. Coskun A., Carobene A., Kilercik M., Serteser M., Sandberg S. et al. (2018). Within-subject and between-subject biological variation estimates of 21 hematological parameters in 30 healthy subjects. Clinical Chemistry and Laboratory Medicine 56(8), 1309-1318. DOI: 10.1515/cclm-2017-1155.

31. Hopkins W., Marshall S., Batterham A., Hanin J. (2009). Progressive statistics for studies in sports medicine and exercise science. Medicine and Science in Sports and Exercise 41(1), 3-13. DOI: 10.1249/MSS.0b013e31818cb278.

32. Beattie C.E., Fahey J.T., Pullinger S.A., Edwards B.J., Robertson C.M. (2021). The sensitivity of countermovement jump, creatine kinase and urine osmolality to 90-min of competitive match-play in elite English Championship football players 48-h post-match. Science and Medicine in Football 5(2), 165-173. DOI: 10.1080/24733938.2020.1828614.

33. Ispiridilis I., Fatouros I.G., Jamurtas A.Z., Nikolaidis M.G., Michaidilis I. et al. (2008). Time-course of changes in inflammatory and performance responses following a soccer 
game. Clinical Journal of Sports Medicine 18(5), 423-431. DOI: 10.1097/JSM.0b013e3181818e0b.

34. Souglis A.G., Papapanagiotou A., Bogdanis G.C., Travlos A.K., Apostolidis N.G., Geladas N.D. (2015). Comparison of inflammatory responses to a soccer match between elite male and female players. Journal of Strength and Conditioning Research 29(5), 1227-1233. DOI: 10.1519/ JSC.0000000000000767.

35. Nescolarde L., Yanguas J., Lukaski H., Alomar X., Rosell-Ferrer J., Rodas G. (2013). Localized bioimpedance to assess muscle injury. Physiological Measurement 34(2), 237245. DOI: 10.1088/0967-3334/34/2/237.

36. Francavilla V.C., Bongiovanni T., Genovesi F., Minafra P., Francavilla G. (2015). Localized bioelectrical impedance analysis: How useful is it in the follow-up of muscle injury? A case report. Medicina dello Sport 68(2), 323-334.

37. Beberashvili I., Azar A., Sinuani I., Kadoshi H., Shapiro G. et al. (2014). Longitudinal changes in bioimpedance phase angle reflect inverse changes in serum IL-6 levels in maintenance hemodialysis patients. Nutrition 30(3), 297-304. DOI: 10.1016/j.nut.2013.08.017.

Submitted: July 16, 2021

Accepted: September 19, 2021 